\title{
Anti-quorum and biofilm formation inhibition by coffee husk oil (Coffee arabica L.).
}

\author{
Hanan M. Al-Yousef*, Musarat Amina \\ Department of Pharmacognosy, College of Pharmacy, King Saud University, Riyadh, Saudi Arabia
}

\begin{abstract}
The volatile oil of the coffee husk of Coffee arabica (Rubiaceae) was obtained by GCMS. This oil showed quorum sensing inhibition activity which were investigated for antipathogenic potential against $P$. aeruginosa (PAO1). The results showed that significant inhibition on the production of virulence $P$. aeruginosa and Biofilm Formation (BF). Moreover, the treatment with sub-MICs of coffee husk oil significantly inhibited the quorum sensing-mediated BF, extracellular polymeric substances production and swarming motility in these pathogens. Wide-spectrum in vitro inhibition of QS controlled virulence factors such as violacein, elastase, pyocyanin, EPS and biofilm in test pathogens was determined.
\end{abstract}

Keywords: Coffee husk oil, Quorum sensing, Biofilm formation, Violacein factors.

Accepted on April 3, 2018

\section{Introduction}

Coffee arabica is one of the most popular food commodities in the world [1]. The huge production and consumption of coffee generates large volumes of residues such as coffee husks [2]. Coffee husk is a mucilaginous fibrous substance containing tannins, caffeine, and phenolic compound [3-5]. Also, some studies showed that coffee husks is rich in protein, carbohydrates, organic matter [6,7] and chemical nutrients such as nitrogen and potassium [8], which makes it perfect substrate for the production of benefit products [9]. Commercially coffee husk have been used as fermented tea, food supplements, and animal feed [10]. Furthermore, very recently coffee husks are reported to be the potential source of antimicrobial and antioxidant activities [11]. In the current paper our focus on Coffee husk, an agro- and food industry wastes that can be utilized as valuable and cheap sources of antimicrobial compounds.

Recently, research efforts are focused on controlling microbial infection through advancing antipathogenic agents which control microbial diseases by inhibiting microbial aggregation process called microbial Quorum Sensing (QS). Quorum aggregation system regulates the release of Pseudomonas virulence factors [12]. QS of $P$. aeruginosa is regulated by signaling molecules claimed N-Acylated Homoserine Lactones (AHLs). The concentration of these molecules rises in relation to the high of bacterial population, those signaling molecules return back to the bacteria to control bacterial pathogenicity [13]. Thereby, removal of QS represents potential advance to manage bacterial virulence and resistance [14].

Literature survey revealed that there is no reported data about coffee husk oil Quorum Sensing Inhibition (QSI) activity. A study was planned to determine the QS and Biofilm Inhibitory properties (BI) of coffee husk oil against pathogenic bacteria using the reporter Chromobacterium violaceum CVO26.

\section{Material and Methods}

\section{Plant material}

The fresh coffee husks of $C$. arabica were collected from the Kholan (Bin Amer region of AbdulAziz Al-Melahe Farm (Sana'a, Yamane), northern border of Saudi Arabia. The plant material was identified and authenticated by Dr. Mahmoud Abdul Aziz Mahmoud,and a voucher specimen $\left(\mathrm{PDH}^{\#} 437\right)$ has been deposited at the herbarium, college of pharmacy, King Saud University, Riyadh.

\section{Essential oil isolation procedure}

Air-dried husks (100 g) obtained from $C$. arabica were subjected to hydrodistallation for 3-4 $\mathrm{h}$ using an all glass Clevenger-type apparatus as described by Al-Yousef et al. [11], to obtain essential oil $0.31 \% \mathrm{v} / \mathrm{w}$. A total of 55 components were analysed in the essential oil and were identified on the basis of GC retention time and comparing with Wiley library 2006 as well as comparison the fragmentation patterns of their mass spectra with those reported in the literatures $[11,15,16]$ and various of the identified components were identified as sesquiterpenes, amides, phenolic, fatty acids, sterols, alkanes furanol, compounds and alcohols [11].

\section{Bacterial strains and growth conditions}

C. violaceum CVO26 (a mini-Tn5 mutant of $C$. violaceum 31532 that cannot synthesize its own AHL but responds to exogenous C4 and C6 AHLs) and P. aeruginosa PAO1 (C4 and 
3-oxo-C12 HSL producer, McLean et al., 2004), bacterial strains were used for the study [17]. Luria-Bertani (LB) medium were used to grow all bacterial strains at $30^{\circ} \mathrm{C}$ for 24 h. When needed, the medium for $C$. violaceum CV026 was supplemented with hexanoyl homoserine lactone (C6-HSL; Sigma-Aldrich, St Louis, MO, USA).

\section{Determination of minimum inhibitory concentration}

Broth macrodilution method was used to determine MIC of the test agents against $C$. violaceum $\mathrm{CVO} 26$ and $P$. aeruginosa PAO1 [18]. Assessment of anti-virulence and anti-biofilm activity in the above test strains were carried out by sub-MICs.

\section{Quantitative estimation of violacein}

Production of violacein by Chromobacterium violaceum (CVO26) in presence of sub-MICs of test agents was studied by extracting violacein and quantifying photometrically using method of Blosser and Gray [19], with little modifications by Husain et al. [20,21]. From each flask, $1 \mathrm{ml}$ of culture was taken up and centrifuged for $10 \mathrm{~min}$ at $13000 \mathrm{rev} / \mathrm{min}$ to precipitate out the insoluble violacein. The supernatant of culture was discarded and $1 \mathrm{ml}$ of DMSO was added to the pellet. In order to completely solubilize violacein, the solution was vigorously vortexed for $30 \mathrm{~s}$ and centrifuged for more 10 $\mathrm{min}$ at $13000 \mathrm{rev} / \mathrm{min}$ to remove the cells. $200 \mu \mathrm{L}$ of supernatants (violacein-containing) were added to 96 -well flat bottomed microplates/ four wells per each solution and the absorbance was read with a microplate reader at $585 \mathrm{~nm}$ wavelength. Reduction in the production of pigment in the presence of test agents was measured in terms of $(\%)$ inhibition as, $((\mathrm{OD}$ of control-OD of treated $) / \mathrm{OD}$ of control $) \times 100$.

\section{Effect on virulence factor production}

Effect of sub-MICs of test agents on virulence factors of PAO1 such as LasB elastase, pyocyanin, swarming motility, extracellular polymeric substances (EPS) extraction and quantification was assessed as described previously $[11,20]$.

\section{Assay for biofilm inhibition}

The effect of test agents on biofilm formation was determined by using the microtitre plate assay of O'Toole and Kotler, [22]. Briefly, $1 \%$ overnight cultures (0.4 OD at $600 \mathrm{~nm}$ ) of test pathogens were added into $1 \mathrm{ml}$ of fresh LB medium in the presence and the absence of sub-MICs of test agents. Bacteria were allowed to adhere and grow without agitation for $24 \mathrm{~h}$ at $30^{\circ} \mathrm{C}$. After incubation, microtitre plate was emptied by removing the media along with free-floating planktonic cells and the wells were gently rinsed twice with sterile water. The surface-attached cells (biofilm) were stained with $200 \mu \mathrm{L}$ of $0.1 \%$ crystal violet (CV) (Hi-media, Mumbai, India) solution. After $15 \mathrm{~min}, \mathrm{CV}$ solution was discarded completely and wells were filled with $200 \mu \mathrm{L}$ of $95 \%$ ethanol to solubilize $\mathrm{CV}$ from the stained cells. The biofilm biomass was then quantified by measuring the absorbance at OD $470 \mathrm{~nm}$ in a microplate reader (Thermo Scientific Multiskan Ex, India).

\section{Statistical analysis}

All experiments were performed in triplicates and the data obtained from experiments were presented as mean values and the difference between control and test were analysed using student's t test.

\section{Results and Discussion}

Hydro-distillation of $C$. arabia husks resulted in isolation of essential oil comprised of fifty five components, which were identified by GC-MS, as reported in our previous study and also the isolated oil have shown significant antibacterial and antioxidant activities [11]. As a continuation of our research [11] on the base of biological screening of obtained essential oil, the present study describes the QS and biofilm inhibitory properties (BI) of coffee husks oil against pathogenic bacteria using the reporter Chromobacterium violaceum CVO26. The coffee husks oil inhibited growth against pathogens, $500 \mu \mathrm{g} / \mathrm{ml}$ for $\mathrm{CV} \mathrm{O} 26$ and $800 \mu \mathrm{g} / \mathrm{ml}$ for PAO1. So, in the current study sub-MIC concentrations $(50-600 \mu \mathrm{g} / \mathrm{ml})$ of coffee husks oil were used for further assays. The purple pigment (Violacein) production in CVO26 is a QS regulated process and its production is organized by CviIR-dependent QS system. In the current study, coffee husks oil inhibited violacein production in wild-type CVO26 strain in concentration dependent action without affecting the population of the bacteria. Maximum significant reduction of $56 \%(\mathrm{P} \leq 0.05)$ was recorded at 400 $\mu \mathrm{g} / \mathrm{ml}$ while at lower concentrations (50-200 $\mu \mathrm{g} / \mathrm{ml}) 11-38 \%$ decrease in violacein was recorded (Figure 1). This dosedependent manner of coffee peel oil on violacein production is in accordance with the reports on Indian medicinal herbs [23], Capparis spinosa and Cuminum cyminum extracts [24].

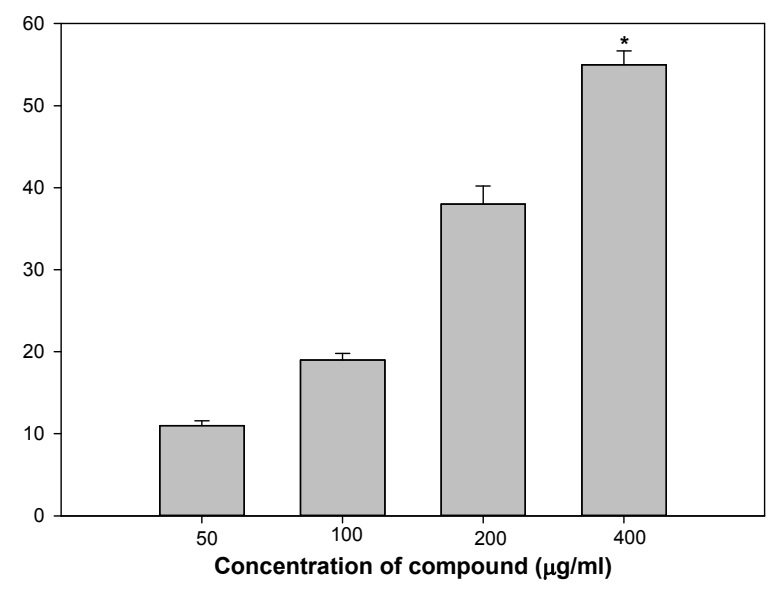

Figure 1. Quantitative assessment of violacein inhibition in CVO26 by sub-MICs of coffee peel. All of the data are presented as mean \pm $S D$. * significance at $p \leq 0.05$. 


\section{Effect of coffee peel oil on virulence factors of PAO1}

Effect of coffee husks oil sub-inhibitory concentrations on virulence factors of PAO1 are showed in Figure 2. Statistically significant decrease in LasB elastase activity was observed in the culture supernatant of PAO1 treated with sub-MICs of coffee husks oil. A minimum of $25 \%$ inhibition was observed when PAO1 was cultured with coffee husks oil at a concentration of $50 \mu \mathrm{g} / \mathrm{ml}$ and maximum significant inhibition of $75 \%(\mathrm{p} \leq 0.005)$ was observed at $400 \mu \mathrm{g} / \mathrm{ml}$ concentration of the extract. Elastase enzyme enhances the growth and invasiveness of the pathogen by degrading the structural components of the infected tissue [25]. In this current investigation, the coffee husk oil demonstrated concentrationdependent inhibition of elastase in PAO1, as shown in (Figure 2 ). This result is in alignment with the study of [26], who demonstrated significant inhibition of LasB activity by edible fruits.

Production of pyocyanin (PP, blue colored) is regulated by QS [27]. Pyocyanin and its precursor phenazine-1-carboxylic acid (PCA) cause neutrophil apoptosis and impairs neutrophilmediated host defense [28]. Coffee peel oil at sub-lethal concentrations exhibited considerable decrease in the PP by PAO1. The maximum significant reduction of $50 \%$ and $59 \%(\mathrm{p}$ $\leq 0.05$ ) in production of pyocyanin was recorded at highest two tested concentrations (200 and $400 \mu \mathrm{g} / \mathrm{ml}$ ) followed by $12 \%$ and $32 \%$ at 50 and $100 \mu \mathrm{g} / \mathrm{ml}$ concentration, respectively (Figure 2). Our results are in agreement with the results of recent reports [29-31] demonstrated that extracts of Tinospora cordifolia (stem) and S. aromaticum (bud) reduced PP significantly.

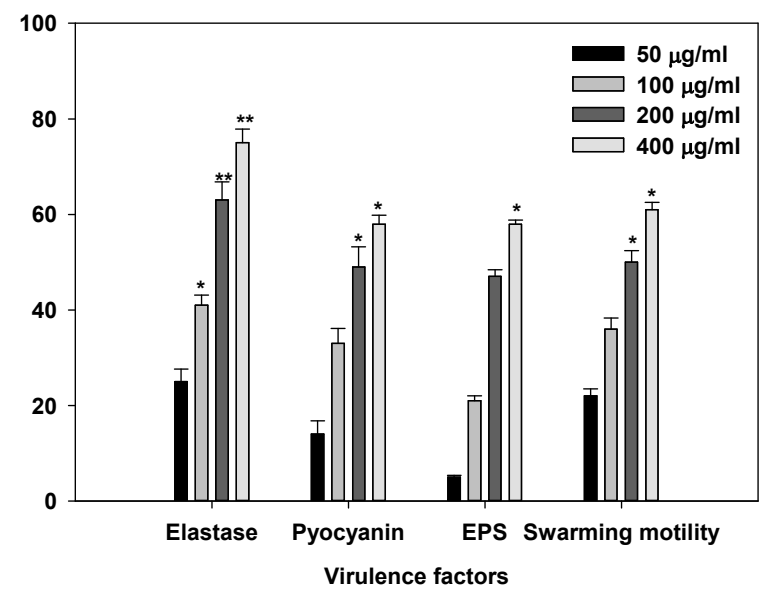

Figure 2. Effect of sub-MICs of coffee peel on inhibition of quorum sensing regulated virulence factors in P. aeruginosa PAO1. All of the data are presented as mean $\pm S D .{ }^{*}$ significance at $p \leq 0.05$, ${ }^{* *}$ significance at $p \leq 0.005$.

Swarming motility and exopolysaccharide production by $P$. aeruginosa plays a pivotal role in the initiation, maturation, and maintenance of the biofilm architecture [32,33].

So, any interference with the motility and exopolysaccharide production is bound to affect the BF by the pathogen. In the current study, treatment of PAO1 with sub-MICs of coffee peel oil showed significantly decrement of exopolysaccharide production at the concentrations of 100 and $200 \mu \mathrm{g} / \mathrm{ml}(\mathrm{p} \leq$ $0.05)$, the extract demonstrated inhibition in exopolysaccharide production to the level of $50 \%$ and $60 \%$ respectively. Similarly, swarming migration of PAO1 was also impaired considerably after treatment with coffee peel oil (Figure 2). This statistically significant reduction of motility and exopolymeric material is reported with Trigonella foenumgraceum seed extract [34].

Biofilm is a drug resistant complex aggregation of microorganisms and is a key factor in the pathogenesis of $P$. aeruginosa [35]. In a biofilm adherent cells become embedded within a slimy extracellular matrix that is composed of EPS. Biofilms are the cause of severe persistent infection and BF is considered as one of the potential drug targets to combat drugresistant chronic infections [36,37]. The coffee peel oil showed $9,29,53$, and $65 \%$ decrease in the BF ability of PAO1 at 50, 100,200 , and $400 \mu \mathrm{g} / \mathrm{ml}$ of extract concentration, respectively (Figure 3). Our observations find support from previous experimentation on $\mathrm{BI}$ in $\mathrm{PAO} 1$ by polyphenolic extract of South Florida plants [38], Lagerstroemia speciosa fruit extract [39], Rosa rugosa [40], standardized extract of Sclerocarya birrea [41], Trigonella foenumgraceum seed extract and Mangifera indica leaf extract [42].

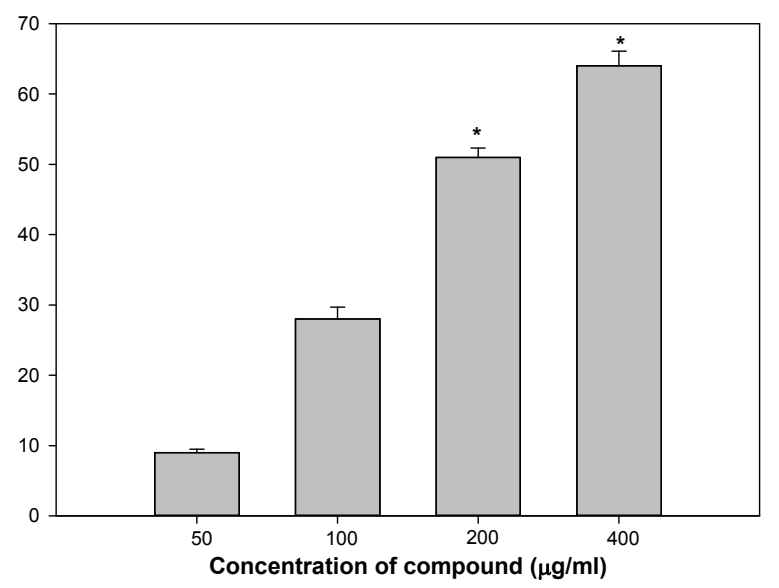

Figure 3. Effect of sub-MICs of coffee peel on biofilm formation in $P$. aeruginosa PAO1. All of the data are presented as mean $\pm S D$. ${ }^{*}$ significance at $p \leq 0.05$.

\section{Conclusion}

Coffee peel oil is known for its uses and our study appends an additional note on its QS and BI properties against pathogenic bacteria. The current study demonstrates that coffee peel oil could inhibit the QS initiate virulence factors production in $C$. violaceum and $P$. aeruginosa. Moreover, the treatment with sub-MICs of coffee peel oil significantly inhibited the QSmediated BF, EPS production and swarming motility in these pathogens. Wide-spectrum in vitro inhibition of QS controlled virulence factors such as violacein, elastase, pyocyanin, EPS and biofilm in test pathogens was determined. Thus, these results postulated that coffee oil has powerful anti-infective 
properties and could confirm to be an effective anti-QS and antibiofilm agent against pathogens.

\section{Acknowledgment}

This research project was supported by a grant from the "Research Center of the Center for Female Scientific and Medical Colleges", Deanship of Scientific Research, King Saud University.

\section{References}

1. Matos AT. Tratamento de resíduos na pós-colheita do café (residues disposal in coffee post-processing). Coffee Sci 2008; 161-201.

2. Garcia AWR, Martins M, Salgado AR, Freire ACF. Efeito da adubac,ão química isoladamente, bem como a sua associac, a ${ }^{\sim}$ com adubos orgẫnicos na produc, a ${ }^{\sim}$ do cafeeiro Mundo Novo. 10th congresso brasileiro de pesquisas cafeeiras, Poc, os de Caldas 1983.

3. Mussatto SI, Machado EMS, Martins S, Teixeira JA. Production, composition, and application of coffee and its industrial residues. Food Bioprocess Technol 2011; 4: 661-672.

4. Pandey A, Soccol CR, Nigam P, Brand D, Mohan R, Roussos S. Biotechnological potential of coffee pulp and coffee husk for bioprocesses. Biochem Eng J 2000; 6: 153-162.

5. Matos AT. Tratamento de resíduos na pós-colheita do café (residues disposal in coffee post-processing). Pós-colheita do Café (coffee post processing). Lavras (Brazil): Editora UFLA 2008; 161-201.

6. Esquivel P, Jimenez VM. Functional properties of coffee and coffee by products. Food Res Int 2012; 46: 488-495.

7. Murthy PS, Nadu MM. Sustainable management of coffee industry by-products and value addition-a review. Resour Conserv Recycl 2012; 66: 45-58.

8. Mussatto SI, Machado EMS, Martins S, Teixeira JA. Production, composition, and application of coffee and its industrial residues. Food Bioprocess Technol 2011; 4: 661-672.

9. Franca AS, Oliveira LS. Coffee processing solid wastes: current uses and future perspectives. Agricultural wastes. New York: Nova Publishers 2009; 155-189.

10. Brand D, Pandey A, Roussos S, Soccol CR. Biological detoxification of coffee husk by filamentous fungi using a solid state fermentation system. Enz Microbiol Technol 2000; 27: 127-133.

11. Al-Yousef HM, Amina M. Essential oil of Coffee arabica L. Husks: A brilliant source of antimicrobial and antioxidant Agents. Biomed Res 2018; 29: 174-180.

12. Zhang LH, Dong YH. Quorum sensing and signal interference: diverse implications. Mol Microbiol 2004; 53: 1563-1567.

13. Fuqua C, Greenberg EP. Listening in on bacteria: acyl homoserine lactone signalling. Nat Rev Mol Cell Boil 2002; 3: 685-695.
14. Hong KW, Koh CL, Sam CK, Yin WF, Chan KG. Quorum quenching revisited-From signal decays to signaling confusion. Sensors (Basel) 2012; 12: 4661-4696.

15. Adams RP. Identification of essential oil components by GC-MS. Allured Publ Corp Carl Stream II 1995.

16. Mclafferty FW, Staffer DB. The Eiley NBS registry of mass spectral data. Wiley Int Public 1989; 1-7.

17. Al-Yousef HM, Ahmed AF, Al-Shabib NA, Laeeq S, Khan RA., Rehman MT, Alsalme A, Al-Ajmi MF, Khan MS, Husain FM. (2017b) Onion peel ethylacetate fraction and its derived constituent quercetin 4'-O- $\beta$-D glucopyranoside attenuates quorum sensing regulated virulence and biofilm formation. Front Microbial 2017.

18. CLSI. Method for antifungal disk diffusion susceptibility testing of yeasts. CLSI Document M44-A.Wayne, PA: CLSI 2004.

19. Blosser RS, Gray KM. Extraction of violacein from Chromobacterium violaceum provides a new quantitative bioassay for $\mathrm{N}$-acyl home serine lactone auto inducers. J Microbial Methods 2000; 40: 47-55.

20. Husain FM, Ahmad I, Khan MS, Ahmad E, Tahseen Q, Khan MS. SubMICs of Mentha piperita essential oil and menthol inhibits AHL mediated quorum sensing and biofilm of Gram negative bacteria. Front Microbiol 2015; 6: 420 .

21. Al-Yousef HM, Amina M. Essential onion peel ethylacetate fraction and its derived constituent quercetin 4'-O- $\beta$-D glucopyranoside attenuates quorum sensing regulated virulence and biofilm. Front. Microbiol 2017.

22. OToole GA, Kolter R. Initiation of biofilm formation in Pseudomonas fluorescens WCS365 proceeds via multiple, convergent signaling pathways: a genetic analysis. Mol Microbiol 1998; 28: 449-461.

23. Zahin M, Hasan S, Aqil F, Khan MSA, Husain FM, Ahmad I. Screening of certain medicinal plants from India for their anti-quorum sensing activity. Indian J Exp Biol 2012, 48: 1219-1224.

24. Sybiya VPIA, Agilandeswari P, Musthafa KS, Pandian SK, Ravi AV. Antibiofilm and quorum sensing inhibitory potential of Cuminum cyminum and its secondary metabolite methyl eugenol against gram negative bacterial pathogens. Food Res Int 2012; 45: 85-92.

25. Kharazmi A. Interactions of Pseudomonas aeruginosa proteases with the cells of the immune system. Antibiot Chemother 1989; 42: 42-49.

26. Musthafa KS, Ravi AV, Annapoorani A, Sybiya Vasantha Packiavathy IA, Pandian SK. Evaluation of anti-quorumsensing activity of edible plants and fruits through inhibition of the $\mathrm{N}$-acyl-homoserine lactone systemin Chromo bacterium violaceum and Pseudomonas aeruginosa. Chemotherapy 2010; 56: 333-339.

27. Williams P. Quorum sensing, communication and cross kingdom signaling in the bacterial world. Microbiology 2007; 153: 3923-3928.

28. Fothergill JL, Panagea S, Hart CA, Walshaw MJ, Pitt TL, Winstanley C. Widespread pyocyanin overproduction 
among isolates of a cystic fibrosis epidemic strain. BMC Microbiol 2007; 7: 45.

29. Krishnan T, Yin WF, Chan KG. Inhibition of quorum sensingcontrolled virulence factor production in Pseudomonas aeruginosa PAO1 by ayurveda spice clove (Syzygium aromaticum) bud extract. Sensors 2012; 12: 4016- 4030.

30. Gala VC, John NR, Bhagwat AM, Datar AG, Kharkar PS, Desai KB. Attenuation of quorum sensing-regulated behaviour by Tinospora cordifolia extract and identification of its active constituents. Indian J Med Res 2016; 144: 92-103.

31. Krishnan T, Yin WF, Chan KG. Inhibition of quorum sensingcontrolled virulence factor production in Pseudomonas aeruginosa PAO1 by ayurveda spice clove (Syzygium aromaticum) bud extract. Sensors 2012; 12: 4016- 4030.

32. Pratt LA, Kolter R. Genetic analysis of Escherichia coli biofilm formation: roles of flagella, motility, chemotaxis and type I pili. Mol Microbial 1998; 30: 285-293.

33. Hentzer M, Wu H, Andersen JB, Riedel K, Rasmussen TB, Bagge N. Attenuation of Pseudomonas aeruginosa virulence by quorum sensing inhibitors. EMBO J 2003; 22: 3803-3815.

34. Husain FM, Ahmad I, Khan MS, Al-Shabib N. Trigonella foenum-graceum (Seed) extract interferes with quorum sensing regulated traits and biofilm formation in the strains of Pseudomonas aeruginosa and Aeromonas hydrophila. Evid Based Complement Alternat Med 2015; 8: 79540.

35. Hall-Stoodley L, Costerton JW, Stoodley P. Bacterial biofilms: from the natural environment to infectious diseases. Nat Rev Microbiol 2004; 2: 95-108.

36. Wu H, Moser C, Wang HZ, Hoiby N, Song ZH. Strategies for combating bacterial biofilm infections. Int J Oral Sci 2015; 7: 1-7.
37. Adonizio A, Kong KF, Mathee K. Inhibition of quorumsensingcontrolled virulence factor production in Pseudomonas aeruginosa by south Florida plant extracts. Antimicrob. Agents Chemother 2008; 52: 198-203.

38. Adonizio A, Kong KF, Mathee K. Inhibition of quorumsensing controlled virulence factor production in Pseudomonas aeruginosa by south Florida plant extracts. Antimicrob Agents Chemother 2008; 52: 198-203.

39. Singh BN, Singh HB, Singh A, Singh BR, Mishra A, Nautiyal CS. Lagerstroemia speciosa fruit extract modulates quorum sensing controlled virulence factor production and biofilm formation in Pseudomonas aeruginosa. Microbiology 2012; 158: 529-538.

40. Zhang, JM, Rui X, Wang L, Dong M. Polyphenolic extract from Rosa rugosatea inhibits bacterial quorum sensing and biofilm formation. Food Control 2014; 42: 125-131.

41. Sarkar R, Chaudhary SK, Sharma A, Yadav KK, Nema NK, Sekhoacha M. Anti-biofilm activity of Marula-astudy with the standardized bark extract. J Ethnopharmacol 2014; 154: 170-175.

42. Husain FM, Ahmad I, Al-thubiani AS, Abulreesh HH, AlHazza IM, Aqil F. Leaf extracts of Mangifera indica L. inhibits quorum sensing regulated production of virulence factors and biofilm in test bacteria. Front Microbiol 2017; 8: 727 .

\section{*Correspondence to}

Hanan M. Al-Yousef

Department of Pharmacognosy

College of Pharmacy

King Saud University

Saudi Arabia 